\title{
Military Training Mission in Iraq: An Exploratory Case Study Research
}

\author{
João Reis, Bruno Reis, Marta Nowakowska, and Aneta Kazanecka
}

\begin{abstract}
The purpose of this paper is to investigate how military training is being conducted by NATO coalition forces in Iraq. Thus, the intent of this paper is to discuss the implications of existing misalignments between the military forces that are providing the training and those receiving it. To that end, we have used an exploratory case study research, which included multiple sources of data collection for corroboration and triangulation purposes. The results that emerged from the content analysis showed two types of outcomes that may be relevant to improve the military training in Iraq. The first outcome is identified as the intangible actions, which were mainly focused on social relations, with the intent of narrowing the cultural gap between the international coalition and Iraqi forces. Without surprising, a second outcome is identified as tangible actions, which were associated with training programs and the establishment of tactics, techniques, and procedures (TTPs) relevant to small and medium military units. Future research should focus on programs of "training the trainers" in order to develop long-term teaching and move forward with sustainable Iraqi Security Forces (ISF).
\end{abstract}

Keywords NATO $\cdot$ Iraq $\cdot$ Social relations • Training program • Tactics • Techniques $\cdot$ Procedures

\footnotetext{
J. Reis (凶)

Department of Military Science, Military Academy, CINAMIL/CISD, Lisbon, Portugal e-mail: joao.reis@academiamilitar.pt

B. Reis

Military Academy, Portuguese Army, Lisbon, Portugal

e-mail: reis.bm@mail.exercito.pt
}

M. Nowakowska · A. Kazanecka

Military Academy of Land Forces, 51-147 Wroclaw, Poland

e-mail: marta.nowakowska@awl.edu.pl

A. Kazanecka
e-mail: aneta.kazanecka@awl.edu.pl

(C) The Editor(s) (if applicable) and The Author(s), under exclusive license 


\section{Introduction}

As cities around the world are getting bigger and bigger and the world population is growing steadily, consequently, megacities $(10$ million +$)$ are rising at a fast pace [1]. This rapid urbanization is also threatening existing social ecosystems due to increased urban hazards such as air pollution [2], gender-based violence [3], just to name a few. Therefore, overcrowded urban areas, together with geopolitical interests, in particular West Asia, are expected to remain a breeding ground for conflict. This is even more dramatic because, in highly populated areas, military activities become more complex, increasing the risks of endangering the lives of thousands of innocent citizens. For a safe and secure environment in these regions, a good first step is to build strong and committed defense and security forces. In that regard, the North Atlantic Treaty Organization (NATO) has been making efforts in stabilizing countries such as Afghanistan and Iraq [4, 5] by conducting training activities to develop longterm skills for its military and police forces [6, 7]. To the best of our knowledge, the existing literature lacks research on topics as military training. Exemplifying, we conducted a fast search on Scopus database, on December 9th, 2019, using the keywords "military training" AND "Iraq" and we found 35 manuscripts; moreover, we increased the span to "training" AND "Iraq" and we found 1,183 documents. Most part of the latter documents focused on medicine (28.3\%), engineering (17.9\%) and a few percentages of social sciences $(14.3 \%)$. Therefore, our objective is to fill that gap in the literature, by conducting exploratory research to discuss the implications from possible misalignments between the military forces that are providing training in Iraq, and those who are receiving it. We believe this research can provide a contribution to military science, which is under the scope of the social sciences field but also provides guidelines to practitioners, in order to improve their training strategies.

The next section of this paper provides a brief literature review to explore the elementary conceptual terms; the next section describes the research methodology, explaining the sources of data collection, data analysis, and issues related to the research validity and reliability; is followed by the results section, which presents the summary of the content analysis; finally, the conclusions that focus on the contributions to the theory and practice, limitations and perspectives for future research.

\section{Literature Review}

There is no precise census in Iraq, the only and best available data on its population dating from 1947 [8]. However, due to population growth, it is estimated that the capital will reach 10 million inhabitants in a few years. The relevance of the training is mainly focused on military operations in urban areas, which were the worst-case scenarios. The above argument is in line with former strategists such as Tzu [9], who stated that the worst policy is to attack cities. Even in today's scenarios, it is quite 
clear that urban warfare causes more prejudice to society than in rural areas, see, for example, the high number of civilian casualties. However, some practices have improving these concerns, such as (1) the high accuracy of military weaponry, which has reduced the risk of civilian causalities; or (2) the military training, which, for example, helps soldiers acquire sufficient social skills to operate in highly populated areas.

In Petraeus's [10] remarks, the early stages of the Iraq war, the liberation army was racing against the clock, because of the extremely high expectations of the Iraqi people, but, in our view, also because of political objectives, which military forces were pressured to achieve in short time frames. On the other hand, patience, empathy, and humility are important factors that may be considered in the ISF's training [11] and therefore it is not in line with hasty decisions. So, it is important to bear in mind that conflicts occur between nations of different cultures [12] and the potential conflict increases with cultures as diverse as those in the Middle East and the West [13]. In fact, cultural awareness is one of the key issues to get more effective training, but also to share experiences between NATO and Iraqi leaders about human rights [14] and gender integration issues [15], just to name a few topics.

Security force assistance (SFA) — training, advising and equipping allied militaries - is an increasingly common US response to threats emanating from weak states [16]. Reinforcing the previous argument, the relevance of training is also well noticeable by the US Army, which has invested in the first and second brigades of the first Infantry Division to train foreign forces including the Iraq forces [17]. The current NATO Mission in Iraq (NMI) is a non-combat training and capacitybuilding mission that is conducted with full respect for Iraq's sovereignty and territorial integrity [18]. Recently, the NATO Secretary General Jens Stoltenberg met with Prime Minister Adil Abdul-Mahdi, and highlighted that NATO's assistance on training Iraqi forces is a key tool in fighting terrorism [19]. Approximately 500 civilian and military personal are attached to the NMI with the bulk assigned to the greater Baghdad area and to the Iraqi military's Camp Taji base and Besmayah range complex, where most of NMI's training activities take place [20, 21]. The investment made so far is in line with political leaders in America and military leaders in Iraq, which have repeatedly emphasized the importance of building up Iraqi security forces as foundation for the rule of law, economic progress, and political stability [22]. Therefore, the ISF is critical to the creation of a legitimate government in Iraq, and to establishing the stability and security vital to Iraq's development [23].

\section{Methodology}

This paper uses a qualitative and exploratory case study research that tries to explain a phenomenon for which there is little data [24]. The field work was carried out in the light infantry brigade "Rey Alfonso XIII" of the Spanish legion, in Almeria, Spain, for two months. We selected the Spanish legion because of their experience in the US-led Operation Inherent Resolve and in the NMI, which aimed to train the Iraqi 
Security Forces (ISF). Due to the nature of the topic to be addressed, we decided to collect the data in a safe and secure environment, otherwise, the researchers would have to move to a war zone. The data collection consisted of a primary source, semi-structured interviews [25], and secondary sources, direct observation [26] and documental analysis [27]. Using multiple data collection sources enhanced triangulation and corroboration, which helps to minimize misrepresentation that may exist when the collection comes from a single source [27].

We started the research with exploratory interviews, this process proved to be useful to find guidance and to help designing the questionnaire [28] of the formal interviews ahead. Once we received authorization to conduct the formal interviews, we followed a strategy known as convenient and snowball sampling [29]. However, we placed a restriction, only highly knowledgeable informants, who were able to view the phenomenon from different perspectives were chosen, according to different functional areas and different levels of responsibility [30]. The semi-structured interviews were conducted between February 21st to April 5th of 2019, at the base Alvarez de Sotomayor in Almeria, Spain, and each interview lasted between 30 and $60 \mathrm{~min}$. The sample consisted of 17 interviews, which was very useful for the topic we proposed to study. The last two interviews did not lead to relevant and distinct ideas from the previous ones, which led us to think that eventually, we have reached theoretical saturation [31].

The direct observations consisted of collecting field notes during the fieldwork, which were recorded in informal environments [26]. Those notes contained the respondents' reactions and expressions to certain types of questions, as well as informal interactions during the training sessions in the field, but also sketches and photographs. That is, for two months the researcher was constantly on the lookout for details and recorded all the interactions with the military in pre- and post-deployment. Usually, the direct observations answered the following questions: who? said what? when? where? and why? To corroborate the previous data, we also used official documents provided by the Spanish military who were on a mission in Iraq and consisted of manuals and standing instructions used during the training operations.

After data were collected, it was time to analyze it according to the qualitative content analysis technique [32, 33]. In order to systematically analyze the content, we have also used a software known as NVivo 11 to easily identify emerging patterns and ideas [34].

To increase the validity and reliability of the paper [27], after the second author has collected and analyzed the data according to the content analysis technique, the first author reviewed the entire methodological process. The latter also wrote the manuscript according to a logical and chronological sequence of the events. The third and fourth authors reviewed the entire article, in particular the methodological process. Additionally, and in order to avoid misinterpretation, all the interviews were recorded with the permission of the informants and subsequently transcribed. The transcripts were then sent to the informants so that they could review and comment on the text to confirm that the text truly reflected its original meaning. Finally, to make the methodological process more consistent, we made an interview protocol 
so that all interviews followed a guideline, but also recorded all observations in a diary, where all the informal conversations were documented, as well as pre- and post-deployment activities.

\section{Findings}

This section presents the results of the case research. It is divided into three subsections: intangible and tangible actions, and the house of training.

\subsection{Intangible Actions}

Intangible actions have been identified as all activities that are not objective or are difficult to measure, such as social empathy, discipline, etc. Whenever Spanish trainers tried to optimize intangible actions, they faced some challenges in dealing with the heterogeneity and the nature of the force.

The heterogeneity of the force was normally associated to cultural, ethnical and religious differences. Some of these aspects are well-identified in the literature, for instance, Gaub [7] states that cultural differences between an Arab and Western military force are hampering the mission. Moreover, variables such as illiteracy, language barriers, and professional gaps turned the training mission more demanding. For instance, according to some respondents, the former Iraqi Army officers used to be more disciplined than the new assigned, which were less motivated. The aforementioned gap was partially explained by the Spanish legionnaires, as they argued the former officers from Saddam's army felt more committed to their country and the Iraq society. However, the respondents also pointed out that commitment does not mean these officers had the required technical skills or tactical proficiency. Some of the Iraqi officers used to fight during the war, but did not have the same standards as the Western armies, which explains the need for additional training-in general, the trainers kept in mind that the technical level of the Iraqi military was quite low. Furthermore, the respondents also reported some relevant issues as the need to motivate the Iraqi military for training. Motivating the military personnel could be achieved by a variety of ways, some examples are provided below: (1) using games to stimulate competition was a good method to enhance the Iraqi soldiers commitment, as they were very competitive and proud of each other when succeeding in tasks; (2) another method was to turn the training more practical, by avoiding PowerPoint presentations or theoretical classes; (3) for some other respondents the ability to create a strong social bond with their Iraqi counterpart was very relevant, and (4) leading by example was a central issue, since Iraqi soldiers were more interested to follow examples than orders.

The latter challenge was more critical since the nature of the force was related to corruption within the Iraqi leadership in addition to the low capability to lead. 
The leadership issue was twofold, the Iraqi officers attained their position by paying for a promotion or by having strong relations with a particular political group (i.e., nepotism), rather than for their military competencies. These last issues undermined the coalition efforts in achieving a stable and peaceful environment.

\subsection{Tangible Actions}

The tangible actions have been identified as all activities that can be measured, such as technical-tactical skills to overcome obstacles in urban areas, impacts on a shooting range, etc. Regarding these actions, we identified some challenges that needed to be mitigated with the measures adopted by the forces of the international coalition. The first challenge was to control absenteeism through incentives that often related to the use of military material during the training period, as the Iraqi military was more interested in testing the military materials than receiving theoretical instructions.

An additional challenge is related to the simplification of technical-tactical procedures (i.e., back to basics), as the vast majority of the audience lacked technical preparation. We found that trainers were used to train in complex environments, using technical procedures, and technologically advanced military materials. When these military personnel had to act in very severe training situations, where basic training conditions are lacking, these situations added additional challenges to Western forces. In that regard, when legionaries trained non-native-speaking counterparts who had technical difficulties and who permanently feared their relatives' life (i.e., these family members were alone at home on many occasions), we realized through the legionnaires' reactions that these conditions both technically and emotionally difficult to manage. On the other hand, it is in this hostile environment that tangible actions are linked to social competences because it is only possible to train in these extreme situations if the international community stimulates relevant social relations with their counterparts.

At the training level, we found another relevant category, which was the struggle in unifying processes at NATO level, so that trainers always train the Iraqi military in the same way and with the same procedures. To some extent, these arguments are corroborated by the NATO-ATP-99, which is a NATO publication that describes a common understanding approach to the planning and execution of a wide range of urban operations. NATO-ATP-99 argues that it does not intend to direct Tactics, Techniques, and Procedures (TTP), which is a national responsibility, while nations are free to adapt the basic considerations presented to their specific training programs and TTP as they judge appropriate [35]. Therefore, NATO should seek to provide standardized training regardless of the nationality of the trainers. Succeeding in this type of environment requires allies and partners building common understanding problems, as well as common visualization of the mission and mutual confidence and trust to operate together [11]. This category is even more relevant in modern warfare that focuses on combat in urban areas, which requires mastering a high number of procedures and control measures to avoid fratricide or civilian casualties. 
The guidelines for combat training in urban areas are too generic and just mentions the objectives to be achieved in each training class. The underlining issue is that those guidelines focus on the goals the force has to achieve, but not how to do it. In sum, a possible solution is to develop basic manuals of procedures - standardization NATO procedures - such as those that already exist for the counter-improved explosive devices.

\subsection{The House of Training}

The house of training (Fig. 1) summarizes the main results of this research. We argue that the NATO military trains the Iraqi security forces in an essential effort to fight terrorism. The training mission and capacity-building have already reached 500 civilians and military personal to develop long-term and self-sufficient training with the ultimate goal of achieving sustainable ISF's. We have found two main roof covers, identified as tangible and intangible actions. Each action has eight pillars, from the intangible side of the house, we realized that the heterogeneity and nature of the force add some challenges to training activities. If pillars such as cultural, ethnical, and

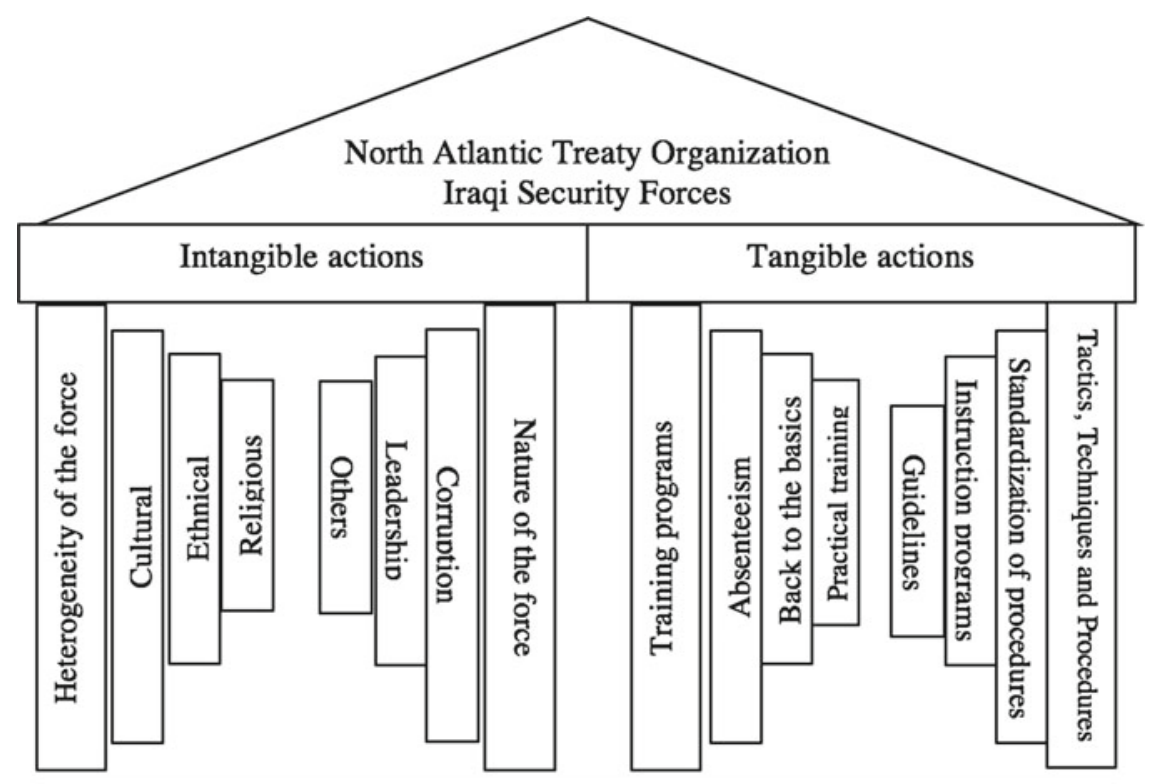

Improve social relations and go back to the basics on the military training

Fig. 1 The house of military training: Iraqi Security Forces versus Spanish Legion (NATO force) 
religious differences are undermining the mission, there are some relevant solutions to motivate Iraqi forces: how to use games to stimulate competition or to make training more practical by avoiding theory classes.

Another issue raised was to collect (tangible) actions to combat the absentee and disinterest of the ISF. In this regard, the possible solutions have been to make training more attractive by going back to basics - in other words - technical and tactical procedures should be more understandable to Iraqi security forces. Jana Kotorova, NATO deputy senior civilian in Iraq, recently highlighted this issue by mentioning that NATO efforts have also established training models that fit Iraqi requirements for reform of Iraq's national security structures and institutions [36]. Overall, we also note that a lot of work must be done by the NATO side, as not all trainers follow standardized procedures; therefore, it is necessary to systematize the training following basic guidelines or manuals of procedures, accessible to the Iraqi security forces. None of these goals can be achieved if the NATO military does not develop proper social relations with the ISF's-because social empathy fosters good working relations [37-39], which may eventually allow military personnel around the world to bridge the gap between themselves, including their counterparts.

\section{Concluding Remarks}

We found a few contributions in the literature about ISF training and how these forces have evolved over time. To fill this gap in the literature, we thought it would be helpful to provide a small contribution to key challenges, limitations, and possible training solutions. Focusing on the latter, the theoretical opportunities to improve the training are to enhance social relations between trainers and their counterparts. In addition, more practical solutions focus on aspects of training standardization and its adaptation to ISF's technical-tactical capabilities.

This paper presents some limitations. First, we only took into consideration data collected from the Spanish legion; the data from the ISF is missing due to difficulties in accessing the study site. Second, the case study itself also presents some limitations, as this paper has no perspectives of generalization, as the results focus on a particular context and specific period of time. In other words, it is generalizable to theoretical prepositions, but not to populations or universes [24]; therefore, these results may not be the same when comparing, e.g., with the Afghan National Security Forces (ANSF) training.

Future research should focus on programs of "training the trainers" in order to develop long-term, self-sufficient training to achieve sustainable ISF in the future. These programs are already ongoing, while few articles already focus on this theme, such as Tigner [20], which argues that NATO's train-the-trainer mission in Iraq is making progress on several fronts, including ordnance disposal, equipment codification, and cyber-awareness training. An alternative to the previous suggestion is to investigate the possibility of gender inclusion training modules in the ISF, which would be useful in a male-dominated context. The challenge of integrating women 
into military and security forces is a hot topic in Western culture [40, 41], so it is likely that the international community and NATO will also try to promote a culture of equality within the ISF-a good first step is to start on the educational/training side.

Acknowledgements Special thanks to the Erasmus + program, which sponsored all the expenses related to data collection in Almeria-Spain, and the Military Academy Research Center (CINAMIL), which funded the conference proceeding. Last but not least, thanks to the Erasmus team of the Portuguese Military Academy, which facilitated the entire process related to the institutional mobility and the anonymous respondents from the Spanish legion, who decisively contributed to the publication of this paper.

\section{References}

1. Zhao, S., Guo, N., Li, C., Smith, C.: Megacities, the world's largest cities unleashed: major trends and dynamics in contemporary global urban development. World Dev. 98, 257-289 (2017)

2. Baklanov, C., Molina, L., Gauss, M.: Megacities, air quality and climate. Atmos. Environ. 126, 235-249 (2016)

3. Jowell, A., Zhou, B., Barry, M.: The impact of megacities on health: preparing for a resilient future. Lancet Planet. Health 1(5), e176-e178 (2017)

4. Saikal, A.: Afghanistan's transition: ISAF's stabilisation role? Third World Q. 27(03), 525-534 (2006)

5. Harris, B.: Stabilizing Iraq: Intelligence Lessons for Afghanistan. The Washington Institute (2009)

6. Lynch, R., Janzen, P.: NATO Training Mission-Iraq: Looking to the Future. National Defense University Washington DC Institute for National Strategic Studies (2006). Retrieved 12 Dec 2019 from https://apps.dtic.mil/dtic/tr/fulltext/u2/a521751.pdf

7. Gaub, F.: Building a New Military? The NATO Training Mission-Iraq. NATO Defense College Research Paper, vol. (67), pp. 2 (2011)

8. Adams, D.: Current population trends in Iraq. Middle East J. 10(2), 151-165 (1956)

9. Tzu, S.: The art of war. In: Strategic Studies, pp. 86-110. Routledge (2014)

10. Petraeus, D. (2006). Learning counterinsurgency: observations from soldiering in Iraq. In: Army Combined Arms Center Fort Leavenworth KS, pp. 1-12 (2006)

11. Donahue, B., Eno, R., Rowan, M.: Their leadership and ownership: concepts for warfare by, with, and through. Infantry Mag. 107(1), 1-62 (2018)

12. Huntington, S.: The Clash of Civilizations and the Remaking of the Modern World. Simon and Schuster, NY (1996)

13. Greaves, S.: A primer of middle Eastern leadership culture. J. Strateg. Secur. 5(4), 99-118 (2012)

14. Katzman, K.: Iraq: Politics, governance, and human rights. In: Library of Congress, Congressional Research Service, Washington DC (2012)

15. Sjoberg, L.: Gender, Justice, and The Wars in Iraq: A Feminist Reformulation of just war Theory. Lexington Books (2006)

16. Biddle, S.: Building security forces and stabilizing nations: the problem of agency. Daedalus 146(4), 126-138 (2017)

17. Kucera, J.: US Army brigades to train foreign forces. Jane's Def. Wkly., 563-564 (2006)

18. NATO.: NATO Mission Iraq (NMI) (2019). Retrieved 9 Dec 2019 from https://www.nato.int/ nato_static_fl2014/assets/pdf/pdf_2019_10/20191023_191023-factsheet-NMI-en.pdf 
19. NATO.: NATO Secretary General in Iraq: Training National Forces is a Key Tool in Fighting Terrorism (2019). Retrieved 9 Dec 2019 from https://www.nato.int/cps/en/natohq/news_ 168923.htm

20. Tigner, B.: NATO's training mission in Iraq gaining momentum. Jane's Def. Wkly. (2019)

21. NATO3.: NATO Mission Iraq (2019). Retrieved 11 Dec 2019 from https://jfcnaples.nato.int/nmi

22. Miska, S.: Growing the Iraqi security forces. Mil. Rev. 85(4), 64 (2005)

23. Cordesman, A., Lanier, S.: Strengthening Iraqi military and security forces. Center for Strategic and International Studies, Washington (2004)

24. Yin, R.: Case Study Research and Applications: Design and Methods. Sage publications (2017)

25. Galletta, A.: Mastering the Semi-structured Interview and Beyond: From Research Design to Analysis and Publication, vol. 18. NYU press (2013)

26. Kothari, C.: Research methodology: methods and techniques. New Age Int. (2004)

27. Mills, A., Durepos, G., Wiebe, E.: Encyclopedia of Case Study Research. Sage (2010)

28. Saunders, M., Lewis, P., Thronhill, A.: Research Methods for Business Students, 4th ed.. Prentice Hall (2007)

29. Given, L.: The Sage Encyclopedia of Qualitative Research Methods. Sage publications (2008)

30. Reis, J., Amorim, M., Melão, N.: Service failure and recovery in technology-based business networks. Int. J. Qual. Serv. Sci. 11(1), 2-15 (2019)

31. Saunders, M., Townsend, K.: Reporting and justifying the number interview participants in organizational and workplace research. Br. J. Manag. 27(4), 836-852 (2016)

32. Drisko, J., Maschi, T.: Content Analysis. Pocket Guides to Social Work. Oxford University Press, Oxford (2015)

33. Neuendorf, K.: The Content Analysis Guidebook. Sage (2016)

34. Skålén, P.: Service marketing control as practice: a case study. Qual. Market Res. Int. J. 14(4), 374-390 (2011)

35. NATO-ATP-99.: Urban tactics. North Atlantic Treaty Organization (2017). Retrieved 12 Dec 2019 from https://standards.globalspec.com/std/10145545/ATP-99

36. NATO4.: NATO Continues to Strengthen Iraqi Security Structure Through New Mission in Iraq (2018). Retrieved 11 Dec 2019 from https://jfcnaples.nato.int/nmi

37. Pastor, I.: Leadership and emotional intelligence: the effect on performance and attitude. Procedia Econ. Fin. 15, 985-992 (2014)

38. Singer, T., Klimecki, O.: Empathy and compassion. Curr. Biol. 24(18), R875-R878 (2014)

39. Preckel, K., Kanske, P., Singer, T.: On the interaction of social affect and cognition: empathy, compassion and theory of mind. Curr. Opin. Behav. Sci. 19, 1-6 (2018)

40. Reis, J., Menezes, S.: Gender inequalities in the military service: a systematic literature review. Sex. Cult. 1-15 (2019). https://doi.org/10.1007/s12119-019-09662-y

41. Reis, J., Gonçalves, R., Menezes, S., Kaczynska, M.: The obstacles women face in gaining access to special operations forces. In: Developments and Advances in Defense and Security, pp. 281-291. Springer, Singapore (2020) 